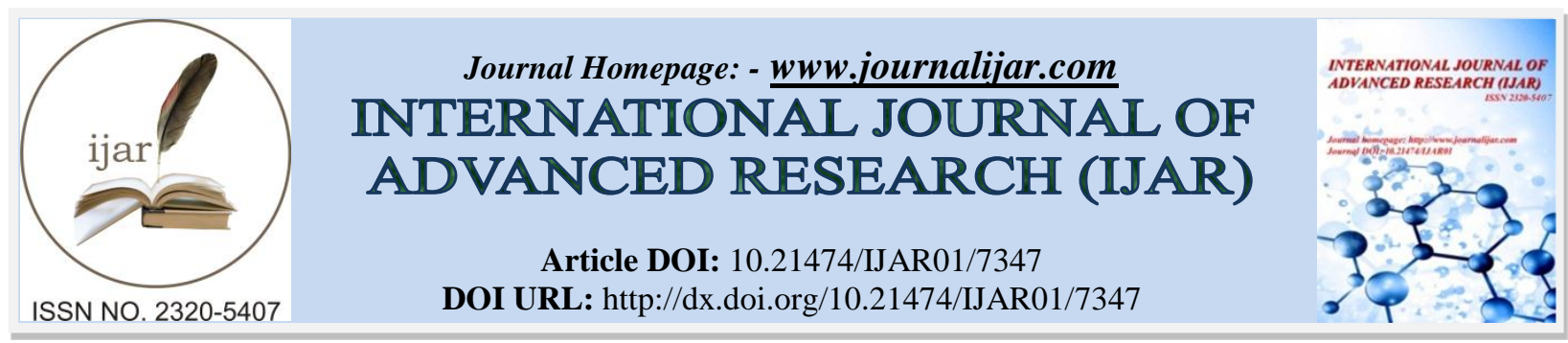

RESEARCH ARTICLE

\title{
PREDICTIVE AND PROGNOSTIC VALUES OF HYPOXIA-INDUCIBLE FACTOR (HIF)-1A AND TAU- PROTEIN EXPRESSION IN SEROUS OVARIAN CANCER (SOC) PATIENTS TREATED WITH CHEMOTHERAPY.
}

\section{Mouhamed A. Fouad ${ }^{1}$, Mona Saeed Mohamed ${ }^{1}$, Rham Z. Ahmed ${ }^{2}$, Basant Sh El Shafaay ${ }^{3}$ and Entsar R Mahdy ${ }^{4}$.}

1. Department of Pathology, Faculty of Medicine, Zagazig University, Zagazig, Egypt.

2. Department of medical oncology, Faculty of Medicine, Zagazig, Egypt.

3. Department of Clinical Oncology and nuclear medicine, Faculty of Medicine, Zagazig University, Zagazig, Egypt.

4. Department of Gynecology and obstetrics, Zagazig University Faculty of Medicine, Zagazig, Egypt.

\section{Manuscript Info}

Manuscript History

Received: 04 May 2018

Final Accepted: 06 June 2018

Published: July 2018

Keywords:-

HIF-1 $\alpha$, Tau protein, hypoxia, serous ovarian carcinoma; chemotherapy, immunohistochemistry.

\section{Abstract}

Background: Serous ovarian carcinoma (SOC) is considered the most common epithelial ovarian malignancies. SOC is still having dismal outcome mainly due to early invasion, spread and resistance to chemotherapeutic agents e.g. platinum based drugs. Recent researches focused on detection of novel therapies and how to overcome chemotherapy resistance in those patients. Hypoxia inducible factor (HIF)-1 $\alpha$ is the transcription factor which is the first detected mediator of cell response to hypoxia in normal and malignant cells.

Tau protein $(50-64 \mathrm{kD})$, which is a gene product that can bind to betatubulin. It was isolated from brain tissue and was associated with many neurodegenerative diseases.

Aim of the study to clarify the predictive and prognostic roles of (HIF)$1 \alpha$ and Tau protein expression in malignant tissues of 40 patients with SOC received paclitaxel first-line chemotherapy.

Methods; we have evaluated expression of HIF-1 $\alpha$ and Tau protein expression by using immunohistochemistry in malignant tissues of forty patients of SOC. We evaluated the predictive and prognostic roles of expression of both proteins in SOC patients that have received firstline chemotherapy. We have followed patients for about three years to assess overall survival rate (OS) and resistance to chemotherapy.

Results: tissue expression of HIF-1 $\alpha$ and Tau-protein in SOC was positively correlated with advanced stage of the tumor $(\mathrm{p}=0.006 \&$ 0.002 respectively), peritoneal implants $(\mathrm{p}=0.005)$, higher grade of the tumor $(\mathrm{p}=0.001 \& 0.008$ respectively $)$, presence of distant metastases $(\mathrm{p}=0.002 \& 0.032$ respectively), presence of ascites $(\mathrm{p}=.034 \& 0.046$ respectively) and L.N metastases $(\mathrm{p}=0.003 \&<0.001$ respectively), chemoresistance $(\mathrm{p}=0.03 \& 0.042$ respectively), recurrence of the disease after successive therapy and unfavorable survival rates $(\mathrm{p}<0.001)$ 
Conclusion: both HIF-1 $\alpha$ and Tau-protein are markers of unfavorable outcome of SOC patients.

Copy Right, IJAR, 2018,. All rights reserved.

\section{Introduction:-}

The $4^{\text {th }}$ commonest type of cancers in females is the epithelial ovarian carcinoma (EOC) [1], the serous subtype is the commonest of all types of EOC [2] Serous ovarian carcinoma (SOC) is still having dismal outcome mainly due to absence of symptoms in the early stage, late diagnosis, early invasion, spread and resistance to chemotherapeutic agents e.g. platinum based drugs [3]. The primary surgical management of SOC is depulking surgery as it has higher rate of invasion and spread to peritoneal cavity via peritoneal fluid [4], surgical management is followed by platinum based chemotherapeutic agents like platinum and taxane therapy [2]; although those agents lead to marked improvement in the management and outcome of SOC patients but the problem is resistance to such chemotherapeutic modalities, the chemotherapy resistance have many mechanisms which become a recent focus of current researches $[\mathbf{5 \&} 6]$. Additionally Recent researches focused on detection of novel therapies and how to overcome chemotherapy resistance in those patients. In addition to its invasive and aggressive nature SOC is a solid rabidly growing tumor which have areas of hypoxia many studies tried to evaluate the role of cancer hypoxia in malignant progression as it is incriminated in progression of many cancers. An easily applied method of assessment of hypoxia is by evaluation of tissue protein expression of Hypoxia inducible factor (HIF)-1 which is a transcription factor that is the primarily detected mediator of cell response to hypoxia [7]. Moreover, growing evidences have linked hypoxia related factors expression and oncogenesis [8].

Tau protein $(50-64 \mathrm{kD})$, which is a product of a gene that is mapped on chromosome 17 and it shows the ability of combination with beta-tubulin in external and internal surface of the microtubules [9]. Tau protein was isolated from brain tissue and was associated with many neurodegenerative diseases [10].

It is essential to clarify factors that are responsible for resistance to platinum based chemotherapy, SOC progression, recurrence and dismal outcome.

Aim of the study to clarify the predictive and prognostic roles of (HIF)-1 $\alpha$ and Tau protein expression in malignant tissues of 40 patients with SOC received paclitaxel first-line chemotherapy.

\section{Patients And Methods:-}

Cases included in our prospective cohort study are forty cases of SOC that were surgically treated in Gynecology and Obstetrics department, faculty of medicine Zagazig University. Samples are processed, diagnosed, graded using WHO grading system [11], and staged using International Federation of Gynecology and Obstetrics systems and tumor-node-metastasis [12], in Pathology department, faculty of medicine Zagazig University. The patients are followed up for 3 years from May 2015 to May 2018 for assessment of response to chemotherapy, recurrence of the disease after successful therapy and for assessment of survival rates in Clinical Oncology and nuclear medicine and Medical Oncology Departments, faculty of medicine Zagazig University. Paraffin blocks from all cases are prepared for immunohistochemical staining for HIF-1 $\alpha$ and Tau protein.

\section{Immunohistochemical staining:}

We have used streptavidin-biotin method in immunohistochemistry [13], where sections have been incubated with primary mouse monoclonal anti-HIF-1 $\alpha$ (Abcam, 1A3) and anti-Tau antibody [E178] (ab32057) antibodies dilution 1:200 (Abcam, Cambridge, MA, USA) at $4{ }^{\circ} \mathrm{C}$ overnight. Positive controls used are sections of lung cancer and normal ovarian epithelial tissue were used as positive control for HIF-1 $\alpha$ and Tau protein respectively [14]. We have evaluated the degree of HIF-1 $\alpha$ and Tau protein immunoreactivity of HIF-1 $\alpha$ and Tau in pathology department, faculty of medicine, Zagazig University.

Evaluation of immunohistochemical expression of HIF-1 $\alpha$ and Tau protein:

HIF-1 $\alpha$ positive cell were evaluated by identification of brown particles in the nucleus of tumor cells and Tau protein positive cells were evaluated by identification of brown particles in the cytoplasm of tumor cells. We considered low expression if $<10 \%$ of tumor cells are positively stained and high expression if $\geq 10 \%$ of tumor cells are positively stained [15]. 


\section{Results:-}

Patients' clinicopathological results;

We have made the current study on 40 cases of female patients with SOC. Their age ranged from (28-78) years. 27 (61.7\%) cases were of high grade and $13(38.3 \%)$ cases were with low grade SOC. Detailed demographic, pathological and follow-up data of patients are found in table 1

\section{Immunohistochemical results of expression of HIF- $1 \alpha$ and Tau-protein in our cases; tables 2\& 3; Figures}

- High tissue expression of HIF-1 $\alpha$ in SOC was found in 28 cases and it was positively correlated with advanced stage of the tumor $(\mathrm{p}=0.006)$, peritoneal implants $(\mathrm{p}=0.005)$, higher grade of the tumor $(\mathrm{p}=0.001)$, presence of distant metastases $(\mathrm{p}=0.002)$, presence of ascites $(\mathrm{p}=.034)$ and L.N metastases $(\mathrm{p}=0.003)$. there is no significant association was found between its expression and bilaterality of the tumor.

- High tissue expression of Tau-protein in SOC was found in 24 cases and it was positively correlated with positively correlated with advanced stage of the tumor $(\mathrm{p}=0.002)$, peritoneal implants $(\mathrm{p}=0.005)$, higher grade of the tumor $(\mathrm{p}=0.008)$, presence of distant metastases $(\mathrm{p}=0.032)$, presence of ascites $(\mathrm{p}=.0 .046)$ and L.N metastases $(\mathrm{p}<0.001)$. no significant association was found between its expression, bilaterality of the tumor or presence of peritoneal implants.

\section{Follow-up results:-}

Tissue expression of HIF-1 $\alpha$ in SOC was positively correlated with chemoresistance $(p=0.03)$, recurrence of the disease after successive therapy and unfavorable survival rates $(\mathrm{p}<0.001)$

Tissue expression of Tau-protein in SOC was positively correlated with chemoresistance $(p=0.03)$, recurrence of the disease after successive therapy and unfavorable survival rates $(\mathrm{p}<0.001)$.

\section{Statistical Analysis:-}

Program used for statistics is SPSS 22.0 for windows (SPSS Inc., Chicago, IL, USA).

Tests used are Mann Whitney U test for non-normally distributed variables. Chi-square test Trend of change for comparison between relative frequencies of ordinal data

Overall Survival (OS) and Recurrence Free Survival (RFS) stratification were done according to markers using the method of Kaplan-Meier plot. A p-value $<0.05$ was significant.

Table 1:-Clinicopathological features, follow-up data and outcome of 40 patients with serous ovarian carcinoma.

\begin{tabular}{|c|c|c|c|c|c|}
\hline \multirow{3}{*}{$\begin{array}{l}\text { Characteristics } \\
\text { Age (years) }\end{array}$} & \multirow{2}{*}{\multicolumn{2}{|c|}{$\begin{array}{l}\text { All patients } \\
(\mathrm{N}=40)\end{array}$}} & \multirow{3}{*}{$\begin{array}{l}\text { Characteristics } \\
\text { Operation }\end{array}$} & \multirow{2}{*}{\multicolumn{2}{|c|}{$\begin{array}{l}\text { All patients } \\
(\mathrm{N}=40)\end{array}$}} \\
\hline & & & & & \\
\hline & & & & & \\
\hline Mean \pm SD & 65.53 & \pm 10.83 & Radical surgery & 10 & $(25 \%)$ \\
\hline Median (Range) & 59 & $(28-78)$ & Suboptimal & 10 & $(30 \%)$ \\
\hline$<40$ years & 4 & $(6.7 \%)$ & Optimal & 20 & $(45 \%)$ \\
\hline 41-59 years & 24 & $(56.7 \%)$ & & & \\
\hline$\geq 60$ years & 12 & $(36.7 \%)$ & & & \\
\hline Positive cytology & & & Number of cycles & \multicolumn{2}{|c|}{$(\mathrm{N}=37)$} \\
\hline Absent & 29 & $(65 \%)$ & 4 cycles & 5 & $(17.5 \%)$ \\
\hline \multirow[t]{2}{*}{ Present } & 11 & $(35 \%)$ & 6 cycles & 3 & $(14 \%)$ \\
\hline & & & 8 cycles & 29 & $(68.4 \%)$ \\
\hline CA125 & & & Response & \multicolumn{2}{|c|}{$(\mathrm{N}=25)$} \\
\hline$\leq 35 \mathrm{U} / \mathrm{ml}$ & 11 & $(35 \%)$ & NR & 10 & $(22.2 \%)$ \\
\hline$>35 \mathrm{U} / \mathrm{ml}$ & 29 & $(65 \%)$ & OAR & 15 & $(77.8 \%)$ \\
\hline Bilaterality & & & Response after $4-6$ cycles & \multicolumn{2}{|c|}{$(\mathrm{N}=25)$} \\
\hline Unilateral & 34 & $(73.3 \%)$ & PD & 3 & $(6.7 \%)$ \\
\hline Bilateral & 6 & $(26.7 \%)$ & SD & 4 & $(22.2 \%)$ \\
\hline Implants & & & PR & 15 & $(64.4 \%)$ \\
\hline Absent & 28 & $(63.3 \%)$ & CR & 3 & $(6.7 \%)$ \\
\hline Present & 12 & $(36.7 \%)$ & & & \\
\hline Ascites & & & Response after 8 cycles & \multicolumn{2}{|c|}{$(\mathrm{N}=25)$} \\
\hline Absent & 28 & $(63.3 \%)$ & $\mathrm{PD}$ & 3 & $(6.7 \%)$ \\
\hline
\end{tabular}




\begin{tabular}{|c|c|c|c|c|c|}
\hline Present & 12 & $(36.7 \%)$ & SD & 5 & $(15.6 \%)$ \\
\hline Grade & & & PR & 5 & $(15.6 \%)$ \\
\hline Low & 13 & $(38.3 \%)$ & $\mathrm{CR}$ & 12 & $(62.2 \%)$ \\
\hline High & 27 & $(61.7 \%)$ & & & \\
\hline LN & & & $\begin{array}{ll}\begin{array}{l}\text { Follow-up } \\
\text { (months) }\end{array} & \text { duration } \\
& \end{array}$ & & \\
\hline Node negative & 11 & $(35 \%)$ & Mean \pm SD & 17.01 & \pm 9.15 \\
\hline Node positive & 29 & $(65 \%)$ & Median (Range) & 11 & $(10-36)$ \\
\hline M & & & Recurrence & $(\mathrm{N}=33)$ & \\
\hline M0 (non-metastatic) & 30 & $(76.7 \%)$ & Absent & 12 & $(27.9 \%)$ \\
\hline M1 (metastatic) & 10 & $(23.3 \%)$ & Present & 21 & $(72.1 \%)$ \\
\hline FIGO Stage & & & Chemosensitivity & $(\mathrm{N}=21)$ & \\
\hline Stage IA & 1 & $(3.3 \%)$ & Chemosensitive & 11 & $(35.5 \%)$ \\
\hline Stage IB & 1 & $(1.7 \%)$ & Chemorefractory & 10 & $(64.5 \%)$ \\
\hline Stage IC & 2 & $(3.3 \%)$ & Death & & \\
\hline Stage IIA & 1 & $(5 \%)$ & Alive & 18 & $(46.7 \%)$ \\
\hline Stage IIB & 3 & $(11.7 \%)$ & Died & 22 & $(53.3 \%)$ \\
\hline Stage IIC & 3 & $(10 \%)$ & & & \\
\hline Stage IIIA & 4 & $(15 \%)$ & & & \\
\hline Stage IIIB & 11 & $(20 \%)$ & & & \\
\hline Stage IIIC & 4 & $(6.7 \%)$ & & & \\
\hline Stage IV & 10 & $(23.3 \%)$ & & & \\
\hline
\end{tabular}

Table 2:-Relation between clinicopathological features and immunohistochemical staining for Hypoxia-Inducible Factor (HIF)-1 $\alpha$, and TAU protein in 40 patients with serous ovarian carcinoma

\begin{tabular}{|c|c|c|c|c|c|c|c|c|c|c|c|c|}
\hline \multirow{2}{*}{$\begin{array}{l}\text { Characterist } \\
\text { ics }\end{array}$} & \multirow{2}{*}{\multicolumn{2}{|c|}{$(\mathrm{N}=40)$}} & \multicolumn{4}{|c|}{ HIF1 $\alpha$} & \multirow{2}{*}{$\begin{array}{l}\mathrm{p}- \\
\text { value }\end{array}$} & \multicolumn{4}{|c|}{ TAU protein } & \multirow{2}{*}{$\begin{array}{l}\mathrm{p}- \\
\text { value }\end{array}$} \\
\hline & & & \multicolumn{2}{|c|}{$\begin{array}{l}\text { Low } \\
(\mathrm{N}=12)\end{array}$} & \multicolumn{2}{|c|}{$\begin{array}{l}\text { High } \\
(\mathrm{N}=28)\end{array}$} & & \multicolumn{2}{|c|}{$\begin{array}{l}\text { Low } \\
(\mathrm{N}=16)\end{array}$} & \multicolumn{2}{|c|}{$\begin{array}{l}\text { High } \\
(\mathrm{N}=24)\end{array}$} & \\
\hline \multicolumn{13}{|l|}{ Age (years) } \\
\hline Mean \pm SD & $\begin{array}{l}65.5 \\
3\end{array}$ & \pm 10.83 & $\begin{array}{l}57.5 \\
4\end{array}$ & \pm 10.20 & $\begin{array}{l}65.1 \\
5\end{array}$ & \pm 7.68 & \multirow[t]{2}{*}{$\begin{array}{l}<0.001 \\
*\end{array}$} & $\begin{array}{l}58.8 \\
8\end{array}$ & \pm 10.06 & $\begin{array}{l}70.6 \\
1\end{array}$ & \pm 7.75 & \multirow[t]{2}{*}{$\begin{array}{l}<0.001 \\
\bullet\end{array}$} \\
\hline $\begin{array}{l}\text { Median } \\
\text { (Range) }\end{array}$ & 57 & $\begin{array}{l}(25 \\
75)\end{array}$ & 46 & $\begin{array}{l}(25- \\
65)\end{array}$ & 69 & $\begin{array}{l}(46- \\
75)\end{array}$ & & 57 & $\begin{array}{l}(25- \\
55)\end{array}$ & 60 & $\begin{array}{l}(56- \\
75)\end{array}$ & \\
\hline$<40$ years & 4 & $(6.7 \%)$ & 4 & $(100 \%$ & 0 & $(0 \%)$ & \multirow[t]{3}{*}{$0.002 \$$} & 4 & $(100 \%$ & 0 & $(0 \%)$ & \multirow[t]{3}{*}{$0.006 \%$} \\
\hline $41-59$ years & 24 & $\begin{array}{l}(56.7 \\
\%)\end{array}$ & 6 & $\begin{array}{l}(44.1 \\
\%)\end{array}$ & 18 & $\begin{array}{l}(55.9 \\
\%)\end{array}$ & & 8 & $\begin{array}{l}(52.9 \\
\%)\end{array}$ & 16 & $\begin{array}{l}(47.1 \\
\%)\end{array}$ & \\
\hline$\geq 60$ years & 12 & $\begin{array}{l}(36.7 \\
\%)\end{array}$ & 2 & $\begin{array}{l}(13.6 \\
\%)\end{array}$ & 10 & $\begin{array}{l}(86.4 \\
\%)\end{array}$ & & 4 & $\begin{array}{l}(18.2 \\
\%)\end{array}$ & 8 & $\begin{array}{l}(81.8 \\
\%)\end{array}$ & \\
\hline \multicolumn{13}{|l|}{$\begin{array}{l}\text { Positive } \\
\text { cytology }\end{array}$} \\
\hline Absent & 29 & $(65 \%)$ & 11 & $\begin{array}{l}(53.8 \\
\%)\end{array}$ & 18 & $\begin{array}{l}(46.2 \\
\%)\end{array}$ & \multirow[t]{2}{*}{$0.02 \$$} & 14 & $\begin{array}{l}(61.5 \\
\%)\end{array}$ & 15 & $\begin{array}{l}(38.5 \\
\%)\end{array}$ & \multirow[t]{2}{*}{$0.009 \$$} \\
\hline Present & 11 & $(35 \%)$ & 1 & $(4.8 \%)$ & 10 & $\begin{array}{l}(95.2 \\
\%)\end{array}$ & & 2 & $(9.5 \%)$ & 9 & $\begin{array}{l}(90.5 \\
\%)\end{array}$ & \\
\hline \multicolumn{13}{|l|}{ CA125 } \\
\hline$\leq 35 \mathrm{U} / \mathrm{ml}$ & 11 & $(35 \%)$ & 9 & $(81 \%)$ & 2 & $(19 \%)$ & \multirow[t]{2}{*}{$0.006 \%$} & 7 & $(81 \%)$ & 4 & $(19 \%)$ & \multirow{2}{*}{$\begin{array}{l}<0.001 \\
+\end{array}$} \\
\hline$>35 \mathrm{U} / \mathrm{ml}$ & 29 & $(65 \%)$ & 3 & $\begin{array}{l}(12.8 \\
\%)\end{array}$ & 26 & $\begin{array}{l}(87.2 \\
\%)\end{array}$ & & 9 & $\begin{array}{l}(23.1 \\
\%)\end{array}$ & 20 & $\begin{array}{l}(76.9 \\
\%)\end{array}$ & \\
\hline \multicolumn{13}{|l|}{ Bilaterality } \\
\hline Unilateral & 34 & $\begin{array}{l}(73.3 \\
\%)\end{array}$ & 10 & $\begin{array}{l}(40.9 \\
\%)\end{array}$ & 24 & $\begin{array}{l}(59.1 \\
\%)\end{array}$ & 0.258 & 13 & $\begin{array}{l}(45.5 \\
\%)\end{array}$ & 21 & $\begin{array}{l}(54.5 \\
\%)\end{array}$ & $0.582 \%$ \\
\hline
\end{tabular}




\begin{tabular}{|c|c|c|c|c|c|c|c|c|c|c|c|c|}
\hline Bilateral & 6 & $\begin{array}{l}(26.7 \\
\%)\end{array}$ & 2 & $(25 \%)$ & 4 & $(75 \%)$ & & 3 & $\begin{array}{l}(37.5 \\
\%)\end{array}$ & 3 & $\begin{array}{l}(62.5 \\
\%)\end{array}$ & \\
\hline \multicolumn{13}{|l|}{ Implants } \\
\hline Absent & 28 & $\begin{array}{l}(63.3 \\
\%)\end{array}$ & 10 & $\begin{array}{l}(52.6 \\
\%)\end{array}$ & 18 & $\begin{array}{l}(47.4 \\
\%)\end{array}$ & \multirow[t]{2}{*}{0.005 \% } & 13 & $\begin{array}{l}(60.5 \\
\%)\end{array}$ & 15 & $\begin{array}{l}(39.5 \\
\%)\end{array}$ & \multirow[t]{2}{*}{0.061 t } \\
\hline Present & 12 & $\begin{array}{l}(36.7 \\
\%)\end{array}$ & 2 & $(9.1 \%)$ & 10 & $\begin{array}{l}(90.9 \\
\%)\end{array}$ & & 3 & $\begin{array}{l}(13.6 \\
\%)\end{array}$ & 9 & $\begin{array}{l}(86.4 \\
\%)\end{array}$ & \\
\hline \multicolumn{13}{|l|}{ Ascites } \\
\hline Absent & 28 & $\begin{array}{l}(63.3 \\
\%)\end{array}$ & 8 & $\begin{array}{l}(47.4 \\
\%)\end{array}$ & 20 & $\begin{array}{l}(52.6 \\
\%)\end{array}$ & \multirow[t]{2}{*}{$0.034 \%$} & 10 & $\begin{array}{l}(52.6 \\
\%)\end{array}$ & 18 & $\begin{array}{l}(47.4 \\
\%)\end{array}$ & \multirow[t]{2}{*}{$0.046 \%$} \\
\hline Present & 12 & $\begin{array}{l}(36.7 \\
\%)\end{array}$ & 4 & $\begin{array}{l}(18.2 \\
\%)\end{array}$ & 8 & $\begin{array}{l}(81.8 \\
\%)\end{array}$ & & 6 & $\begin{array}{l}(27.3 \\
\%)\end{array}$ & 6 & $\begin{array}{l}(72.7 \\
\%)\end{array}$ & \\
\hline \multicolumn{13}{|l|}{ Grade } \\
\hline Low & 13 & $\begin{array}{l}(38.3 \\
\%)\end{array}$ & 8 & $\begin{array}{l}(78.3 \\
\%)\end{array}$ & 5 & $\begin{array}{l}(21.7 \\
\%)\end{array}$ & \multirow[t]{2}{*}{$\begin{array}{l}<0.001 \\
+\end{array}$} & 10 & $\begin{array}{l}(82.6 \\
\%)\end{array}$ & 3 & $\begin{array}{l}(17.4 \\
\%)\end{array}$ & \multirow[t]{2}{*}{$0.008 t$} \\
\hline High & 27 & $\begin{array}{l}(61.7 \\
\%)\end{array}$ & 4 & $\begin{array}{l}(10.8 \\
\%)\end{array}$ & 23 & $\begin{array}{l}(89.2 \\
\%)\end{array}$ & & 6 & $\begin{array}{l}(18.9 \\
\%)\end{array}$ & 21 & $\begin{array}{l}(81.1 \\
\%)\end{array}$ & \\
\hline \multicolumn{13}{|l|}{$\mathrm{LN}$} \\
\hline $\begin{array}{l}\text { Node } \\
\text { negative }\end{array}$ & 11 & $(35 \%)$ & 10 & $(81 \%)$ & 1 & $(19 \%)$ & \multirow[t]{2}{*}{$0.003 t$} & 7 & $(81 \%)$ & 4 & $(19 \%)$ & \multirow[t]{2}{*}{$\begin{array}{l}<0.001 \\
t\end{array}$} \\
\hline $\begin{array}{l}\text { Node } \\
\text { positive }\end{array}$ & 29 & $(65 \%)$ & 2 & $\begin{array}{l}(12.8 \\
\%)\end{array}$ & 27 & $\begin{array}{l}(87.2 \\
\%)\end{array}$ & & 9 & $\begin{array}{l}(23.1 \\
\%)\end{array}$ & 20 & $\begin{array}{l}(76.9 \\
\%)\end{array}$ & \\
\hline \multicolumn{13}{|l|}{$\mathrm{M}$} \\
\hline $\begin{array}{l}\text { M0 (non- } \\
\text { metastatic) }\end{array}$ & 30 & $\begin{array}{l}(76.7 \\
\%)\end{array}$ & 10 & $\begin{array}{l}(45.7 \\
\%)\end{array}$ & 20 & $\begin{array}{l}(54.3 \\
\%)\end{array}$ & \multirow[t]{2}{*}{$0.002 \ddagger$} & 14 & $\begin{array}{l}(52.2 \\
\%)\end{array}$ & 16 & $\begin{array}{l}(47.8 \\
\%)\end{array}$ & \multirow[t]{2}{*}{$0.032 \ddagger$} \\
\hline $\begin{array}{l}\text { M1 } \\
\text { (metastatic) }\end{array}$ & 10 & $\begin{array}{l}(23.3 \\
\%)\end{array}$ & 2 & $(7.1 \%)$ & 8 & $\begin{array}{l}(92.9 \\
\%)\end{array}$ & & 2 & $\begin{array}{l}(14.3 \\
\%)\end{array}$ & 8 & $\begin{array}{l}(85.7 \\
\%) \\
\end{array}$ & \\
\hline \multicolumn{13}{|l|}{ FIGO Stage } \\
\hline Stage IA & 1 & $(3.3 \%)$ & 1 & $\begin{array}{l}(100 \% \\
)\end{array}$ & 0 & $(0 \%)$ & \multirow[t]{10}{*}{$0.006 \S$} & 1 & $(100 \%$ & 0 & $(0 \%)$ & \multirow[t]{10}{*}{$0.002 \S$} \\
\hline Stage IB & 1 & $(1.7 \%)$ & 1 & $(100 \%$ & 0 & $(0 \%)$ & & 1 & $(100 \%$ & 0 & $(0 \%)$ & \\
\hline Stage IC & 2 & $(3.3 \%)$ & 2 & $\begin{array}{l}(100 \% \\
)\end{array}$ & 0 & $(0 \%)$ & & 2 & $(100 \%$ & 0 & $(0 \%)$ & \\
\hline Stage IIA & 1 & $(5 \%)$ & 1 & $\begin{array}{l}(100 \% \\
)\end{array}$ & 0 & $(0 \%)$ & & 1 & $(100 \%$ & 0 & $(0 \%)$ & \\
\hline Stage IIB & 3 & $\begin{array}{l}(11.7 \\
\%)\end{array}$ & 2 & $\begin{array}{l}(71.4 \\
\%)\end{array}$ & 1 & $\begin{array}{l}(28.6 \\
\%)\end{array}$ & & 3 & (100\% & 0 & $(0 \%)$ & \\
\hline Stage IIC & 3 & $(10 \%)$ & 2 & $\begin{array}{l}(66.7 \\
\%)\end{array}$ & 1 & $\begin{array}{l}(33.3 \\
\%)\end{array}$ & & 1 & $\begin{array}{l}(66.7 \\
\%)\end{array}$ & 2 & $\begin{array}{l}(33.3 \\
\%)\end{array}$ & \\
\hline Stage IIIA & 4 & $(15 \%)$ & 1 & $\begin{array}{l}(11.1 \\
\%)\end{array}$ & 3 & $\begin{array}{l}(88.9 \\
\%)\end{array}$ & & 1 & $\begin{array}{l}(33.3 \\
\%)\end{array}$ & 3 & $\begin{array}{l}(66.7 \\
\%)\end{array}$ & \\
\hline Stage IIIB & 11 & $(20 \%)$ & 2 & $\begin{array}{l}(16.7 \\
\%)\end{array}$ & 9 & $\begin{array}{l}(83.3 \\
\%)\end{array}$ & & 2 & $\begin{array}{l}(16.7 \\
\%)\end{array}$ & 9 & $\begin{array}{l}(83.3 \\
\%)\end{array}$ & \\
\hline Stage IIIC & 4 & $(6.7 \%)$ & 0 & $(0 \%)$ & 4 & (100\% & & 2 & $(50 \%)$ & 2 & $(50 \%)$ & \\
\hline Stage IV & 10 & $\begin{array}{l}(23.3 \\
\%)\end{array}$ & 0 & $(0 \%)$ & 10 & $\begin{array}{l}(100 \% \\
\end{array}$ & & 2 & $\begin{array}{l}(14.3 \\
\%)\end{array}$ & 8 & $\begin{array}{l}(85.7 \\
\%)\end{array}$ & \\
\hline \multicolumn{13}{|l|}{ HIF } \\
\hline Low & 12 & $\begin{array}{l}(36.7 \\
\%)\end{array}$ & & & & & & 12 & $(100 \%$ & 0 & $(0 \%)$ & \multirow[t]{3}{*}{$\begin{array}{l}<0.001 \\
+\end{array}$} \\
\hline High & 28 & $\begin{array}{l}(63.3 \\
\%)\end{array}$ & & & & & & 4 & $\begin{array}{l}(10.5 \\
\%)\end{array}$ & 24 & $\begin{array}{l}(89.5 \\
\%)\end{array}$ & \\
\hline TAU & & & & & & & & & & & & \\
\hline
\end{tabular}




\begin{tabular}{|l|l|l|l|l|l|l|l|l|l|l|l|l|l|l|l|}
\hline Low & 16 & $\begin{array}{l}(43.3 \\
\%)\end{array}$ & 12 & $\begin{array}{l}(84.6 \\
\%)\end{array}$ & 4 & $\begin{array}{l}(15.4 \\
\%)\end{array}$ & $\begin{array}{l}<0.001 \\
+\end{array}$ & & & & & \\
\cline { 1 - 7 } & 24 & $\begin{array}{l}(56.7 \\
\%)\end{array}$ & 0 & $(0 \%)$ & 24 & $\begin{array}{l}(100 \% \\
)\end{array}$ & & & & & & \\
\hline
\end{tabular}

*Independent samples Student's test; • Mann Whitney U test; $\$$ Chi-square test; § Chi-square test for trend; $<<0.05$ is significant.

Table 3:-Relation between immunohistochemical staining for Hypoxia-Inducible Factor (HIF)-1 $\alpha$, and TAU protein in 40 patients with serous ovarian carcinoma

\begin{tabular}{|c|c|c|c|c|c|c|c|c|c|c|c|c|}
\hline \multirow[t]{2}{*}{ Characteristics } & \multirow{2}{*}{\multicolumn{2}{|c|}{ All }} & \multicolumn{4}{|c|}{ HIF $\alpha$} & \multirow{2}{*}{$\begin{array}{l}\mathrm{p}- \\
\text { value }\end{array}$} & \multicolumn{4}{|c|}{ Tau } & \multirow[t]{2}{*}{ p-value } \\
\hline & & & \multicolumn{2}{|c|}{ Low } & \multicolumn{2}{|c|}{ High } & & \multicolumn{2}{|c|}{ Low } & \multicolumn{2}{|c|}{ High } & \\
\hline Operation & \multicolumn{2}{|c|}{$(\mathrm{N}=40)$} & \multicolumn{2}{|c|}{$(\mathrm{N}=12)$} & \multicolumn{2}{|c|}{$(\mathrm{N}=28)$} & & \multicolumn{2}{|c|}{$(\mathrm{N}=16)$} & \multicolumn{2}{|c|}{$(\mathrm{N}=24)$} & \multirow{4}{*}{$<0.001$} \\
\hline Radical surgery & 10 & $(25 \%)$ & 13 & $(59.1 \%)$ & 2 & $(5.3 \%)$ & \multirow[t]{3}{*}{$<0.001$ t } & 13 & $(50 \%)$ & 2 & $(5.9 \%)$ & \\
\hline Suboptimal & 10 & $(25 \%)$ & 2 & $(9.1 \%)$ & 16 & $(42.1 \%)$ & & 4 & $(15.4 \%)$ & 14 & \begin{tabular}{|l|l|}
$(41.2 \%)$ \\
\end{tabular} & \\
\hline Optimal & 20 & $(50 \%)$ & 7 & $(31.8 \%)$ & 20 & $(52.6 \%)$ & & 9 & $(34.6 \%)$ & 18 & \begin{tabular}{|l|l}
$(52.9 \%)$ \\
\end{tabular} & \\
\hline ECOG PS & \multicolumn{2}{|c|}{$(\mathrm{N}=40)$} & \multicolumn{2}{|c|}{$(\mathrm{N}=12)$} & \multicolumn{2}{|c|}{$(\mathrm{N}=28)$} & & \multicolumn{2}{|c|}{$(\mathrm{N}=16)$} & \multicolumn{2}{|c|}{$(\mathrm{N}=24)$} & \\
\hline ECOG 1 & 22 & $(70 \%)$ & 17 & $(77.3 \%)$ & 25 & $(65.8 \%)$ & $0.350 \%$ & 20 & $(76.9 \%)$ & 18 & \begin{tabular}{|l|}
$(64.7 \%)$ \\
\end{tabular} & $0.306 \%$ \\
\hline ECOG 2 & 18 & $(30 \%)$ & 5 & $(22.7 \%)$ & 13 & $(34.2 \%)$ & & 6 & $(23.1 \%)$ & 12 & $(35.3 \%)$ & \\
\hline $\begin{array}{ll}\begin{array}{l}\text { Number } \\
\text { cycles }\end{array} & \text { of } \\
\end{array}$ & \multicolumn{2}{|c|}{$(\mathrm{N}=37)$} & $(\mathrm{N}=$ & 17) & $(\mathrm{N}$ & $=20)$ & & $(\mathrm{N}=$ & =13) & $(\mathrm{N}=$ & $=24)$ & \\
\hline 4 cycles & 5 & $(17.5 \%)$ & 3 & $(42.1 \%)$ & 2 & $(5.3 \%)$ & $0.002 \%$ & 8 & $(34.8 \%)$ & 2 & $(5.9 \%)$ & $0.010 \%$ \\
\hline 6 cycles & 3 & $(14 \%)$ & 1 & $(21.1 \%)$ & 2 & $(10.5 \%)$ & & 4 & $(17.4 \%)$ & 4 & $(11.8 \%)$ & \\
\hline 8 cycles & 29 & $(68.4 \%)$ & 13 & $(36.8 \%)$ & 16 & $(84.2 \%)$ & & 11 & $(47.8 \%)$ & 28 & $(82.4 \%)$ & \\
\hline Response & $(\mathrm{N}=$ & 25) & $(\mathrm{N}=$ & & $(\mathrm{N}$ & $=16)$ & & $(\mathrm{N}=$ & $=13)$ & $(\mathrm{N}=$ & $=32)$ & \\
\hline NR & 10 & $(22.2 \%)$ & 0 & $(0 \%)$ & 10 & $(27.8 \%)$ & $0.003 t$ & 0 & $(0 \%)$ & 10 & $(31.3 \%)$ & $0.042 \ddagger$ \\
\hline OAR & 15 & $(77.8 \%)$ & 9 & $(100 \%)$ & 6 & $(77.8 \%)$ & & 13 & $(100 \%)$ & 22 & $(68.8 \%)$ & \\
\hline $\begin{array}{l}\text { Response after 4- } \\
6\end{array}$ & $(\mathrm{~N}=$ & $25)$ & $(\mathrm{N}=$ & & $(\mathrm{N}$ & $=16)$ & & $(\mathrm{N}=$ & =13) & $(\mathrm{N}=$ & $=12)$ & \\
\hline $\mathrm{PD}$ & 3 & $(6.7 \%)$ & 0 & $(0 \%)$ & 3 & $(8.3 \%)$ & $0.04 \$$ & 0 & $(0 \%)$ & 3 & $(9.4 \%)$ & $0.557 \dagger$ \\
\hline SD & 4 & $(22.2 \%)$ & 1 & $(11.1 \%)$ & 9 & $(25 \%)$ & & 2 & $(15.4 \%)$ & 8 & $(25 \%)$ & \\
\hline $\mathrm{PR}$ & 15 & $(64.4 \%)$ & 8 & $(88.9 \%)$ & 11 & $(58.3 \%)$ & & 10 & $(76.9 \%)$ & 19 & $(59.4 \%)$ & \\
\hline $\mathrm{CR}$ & 3 & $(6.7 \%)$ & 0 & $(0 \%)$ & 3 & $(8.3 \%)$ & & 1 & $(7.7 \%)$ & 2 & \begin{tabular}{|l|}
$(6.3 \%)$ \\
\end{tabular} & \\
\hline Response after 8 & $(\mathrm{~N}=$ & 25) & $(\mathrm{N}=$ & & $(\mathrm{N}$ & $=26)$ & & $(\mathrm{N}=$ & $=13)$ & $(\mathrm{N}=$ & $=12)$ & \\
\hline $\mathrm{PD}$ & 3 & $(6.7 \%)$ & 0 & $(0 \%)$ & 3 & $(8.3 \%)$ & $0.009 \$$ & 0 & $(0 \%)$ & 3 & $(9.4 \%)$ & $0.036 t$ \\
\hline SD & 5 & $(15.6 \%)$ & 0 & $(0 \%)$ & 7 & $(19.4 \%)$ & & 0 & $(0 \%)$ & 7 & $(21.9 \%)$ & \\
\hline PR & 5 & $(15.6 \%)$ & 1 & $(11.1 \%)$ & 6 & $(16.7 \%)$ & & 2 & $(15.4 \%)$ & 5 & $(15.6 \%)$ & \\
\hline $\mathrm{CR}$ & 12 & $(62.2 \%)$ & 8 & $(88.9 \%)$ & 20 & $(55.6 \%)$ & & 11 & $(84.6 \%)$ & 7 & $(53.1 \%)$ & \\
\hline Recurrence & $(\mathrm{N}=$ & :33) & $(\mathrm{N}=$ & 21) & $(\mathrm{N}$ & $=22)$ & & $(\mathrm{N}=$ & $=14)$ & $(\mathrm{N}=$ & $=12)$ & \\
\hline Absent & 12 & $(27.9 \%)$ & 11 & $(52.4 \%)$ & 1 & $(4.5 \%)$ & $<0.001+$ & 12 & $(50 \%)$ & 0 & $(0 \%)$ & $<0.001 t$ \\
\hline Present & 21 & $(72.1 \%)$ & 10 & $(47.6 \%)$ & 21 & $(95.5 \%)$ & & 12 & $(50 \%)$ & 19 & $(100 \%)$ & \\
\hline Chemosensitivity & $(\mathrm{N}=$ & 21) & $(\mathrm{N}=$ & 10) & $(\mathrm{N}$ & $=21)$ & & $(\mathrm{N}=$ & $=12)$ & $(\mathrm{N}=$ & $=12)$ & \\
\hline Chemosensitive & 10 & $(35.5 \%)$ & 6 & $(60 \%)$ & 5 & $(23.8 \%)$ & $0.04 \$$ & 7 & $(58.3 \%)$ & 4 & $(21.1 \%)$ & $0.046 \%$ \\
\hline Chemorefractory & 11 & $(64.5 \%)$ & 4 & $(40 \%)$ & 16 & $(76.2 \%)$ & & 5 & $(41.7 \%)$ & 15 & $(78.9 \%)$ & \\
\hline RFS & $(\mathrm{N}=$ & 23) & $(\mathrm{N}=$ & 21) & $(\mathrm{N}$ & $=22)$ & & $(\mathrm{N}=$ & $=20)$ & $(\mathrm{N}=$ & $=12)$ & \\
\hline $\begin{array}{l}\text { Mean (months) } \\
(95 \% \mathrm{CI})\end{array}$ & $\begin{array}{l}20.2 \\
(16\end{array}$ & $\begin{array}{l}2 \text { months } \\
9-23.5)\end{array}$ & & $\begin{array}{l}\text { nonths } \\
3-30.7)\end{array}$ & $\begin{array}{l}14 . \\
(11 \\
17 .\end{array}$ & $\begin{array}{l}6 \text { months } \\
.3 \\
9)\end{array}$ & $0.002 \dagger$ & $\begin{array}{l}25 . \\
(20 \\
29 .\end{array}$ & $\begin{array}{l}3 \text { months } \\
.9 \\
8)\end{array}$ & $\begin{array}{l}13 . \\
(10 \\
17 .\end{array}$ & $\begin{array}{l}9 \text { months } \\
.5 \\
3)\end{array}$ & $<0.001 \dagger$ \\
\hline 1 year RFS & 48.8 & & 71. & & 27. & $3 \%$ & & 70. & $8 \%$ & 21. & $1 \%$ & \\
\hline 2 year RFS & 31. & & 52. & & 10. & $9 \%$ & & 48. & $7 \%$ & 10. & $5 \%$ & \\
\hline 3 year RFS & 23.2 & & 52. & & --- & & & 48. & & --- & & \\
\hline Death & $(\mathrm{N}=$ & 40) & & 22) & & $=28)$ & & $(\mathrm{N}=$ & $=22)$ & $(\mathrm{N}=$ & $=22)$ & \\
\hline Alive & 18 & $(46.7 \%)$ & 19 & $(86.4 \%)$ & 9 & $(23.7 \%)$ & $<0.001$ & 22 & $(84.6 \%)$ & 6 & $(17.6 \%)$ & $<0.001 t$ \\
\hline Died & 22 & $(53.3 \%)$ & 3 & $(13.6 \%)$ & 29 & $(76.3 \%)$ & & \begin{tabular}{|l|}
4 \\
\end{tabular} & $(15.4 \%)$ & 28 & $(82.4 \%)$ & \\
\hline
\end{tabular}




\begin{tabular}{|c|c|c|c|c|c|c|c|}
\hline OS & $(\mathrm{N}=40)$ & $(\mathrm{N}=22)$ & $(\mathrm{N}=28)$ & & $(\mathrm{N}=22)$ & $(\mathrm{N}=22)$ & \\
\hline $\begin{array}{l}\text { Mean (months) } \\
(95 \% \mathrm{CI})\end{array}$ & $\begin{array}{l}22.3 \text { months } \\
(19-25.5)\end{array}$ & $\begin{array}{l}32.6 \text { months } \\
(29-36.2)\end{array}$ & $\begin{array}{l}15.8 \text { months } \\
(12.5 \\
19.1)\end{array}$ & \multirow[t]{4}{*}{$<0.001 \dagger$} & $\begin{array}{l}32.2 \text { months } \\
(28.7 \\
35.6)\end{array}$ & $\begin{array}{l}14.7 \text { months } \\
(11.6 \\
17.8)\end{array}$ & \multirow[t]{4}{*}{$<0.001 \dagger$} \\
\hline 1 year OS & $44.9 \%$ & $86.4 \%$ & $19.7 \%$ & & $84.6 \%$ & $15.1 \%$ & \\
\hline 2 year OS & $44.9 \%$ & $86.4 \%$ & $19.7 \%$ & & $84.6 \%$ & $15.1 \%$ & \\
\hline 3 year OS & $44.9 \%$ & $86.4 \%$ & $19.7 \%$ & & $84.6 \%$ & $15.1 \%$ & \\
\hline
\end{tabular}

95\%CI: 95\%Confidence Interval; $\ddagger$ Chi-square test; $\uparrow$ Log rank test; $p<0.05$ is significant.

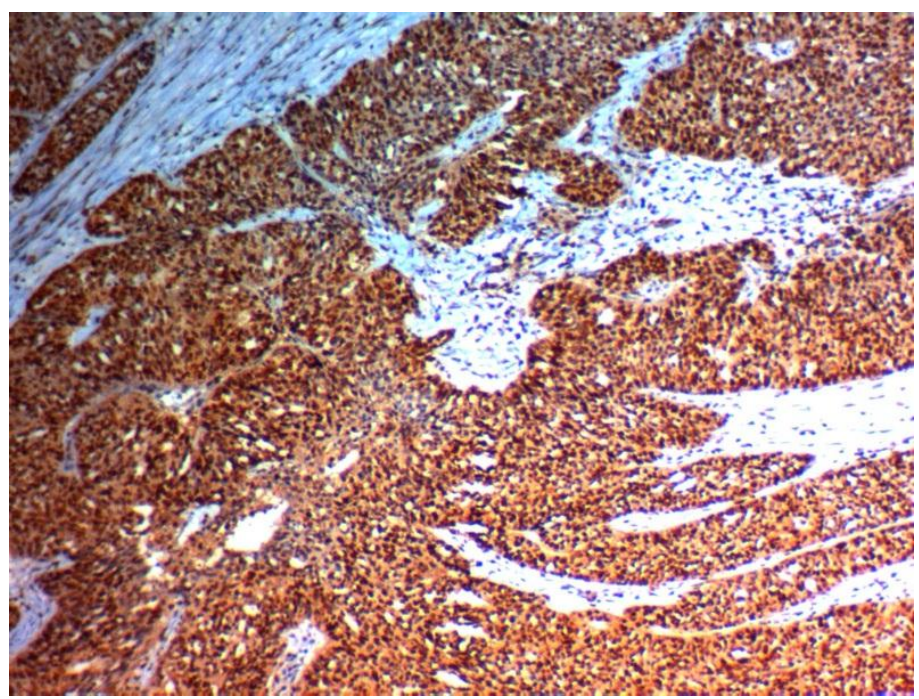

Fig $1 \mathrm{~A}$

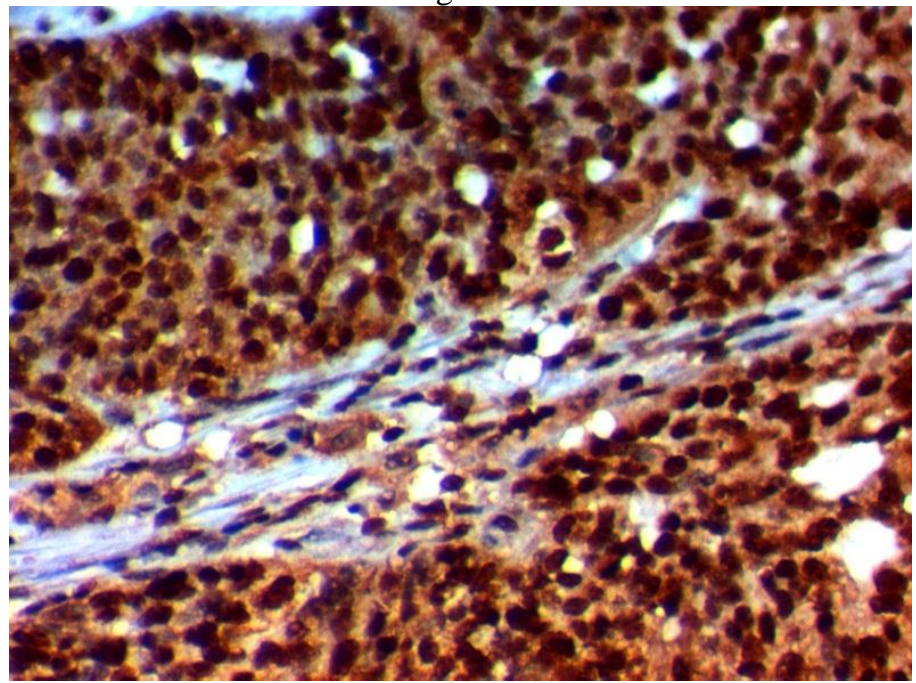

Fig 1 B 


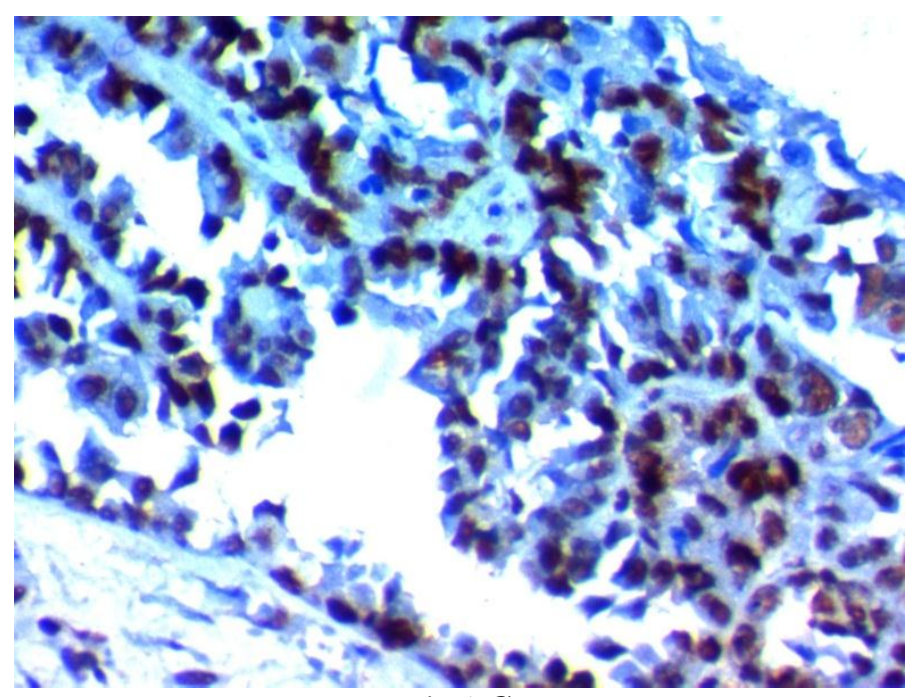

Fig $1 \mathbf{C}$

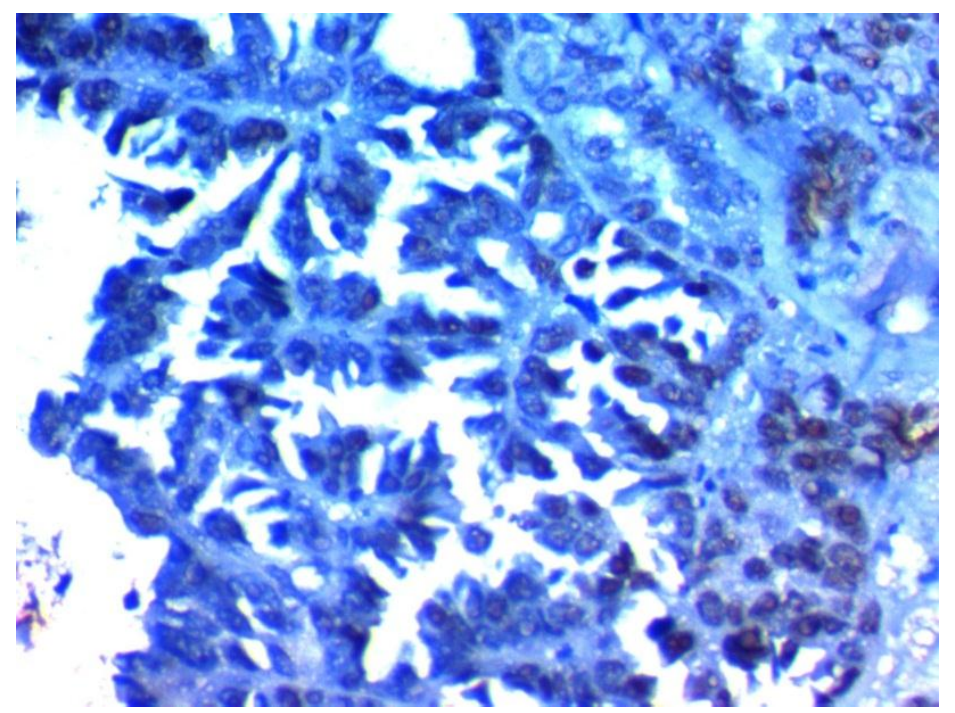

Fig 1 D

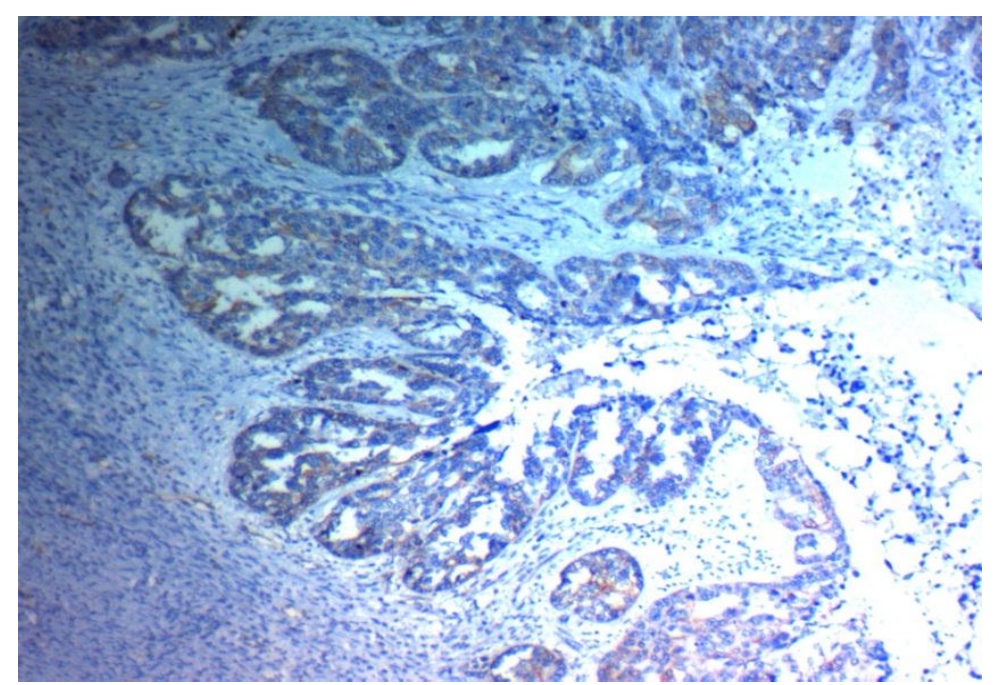

Fig $1 \mathbf{E}$ 
Figure1:-Immunohistochemical expression of Hypoxia-Inducible Factor (HIF)-1 $\alpha$ in serous ovarian carcinoma (SOC): (A) High expression in the nucleus of high grade SOC stage IV x100. (B) High expression in the nucleus of high grade SOC stage IV x400. (C) High expression in the nucleus of high grade SOC stage III x400. ) (D) Low expression in the nucleus of low grade SOC stage IIx400 (E) Low expression in the nucleus of low grade SOC stage Ix100

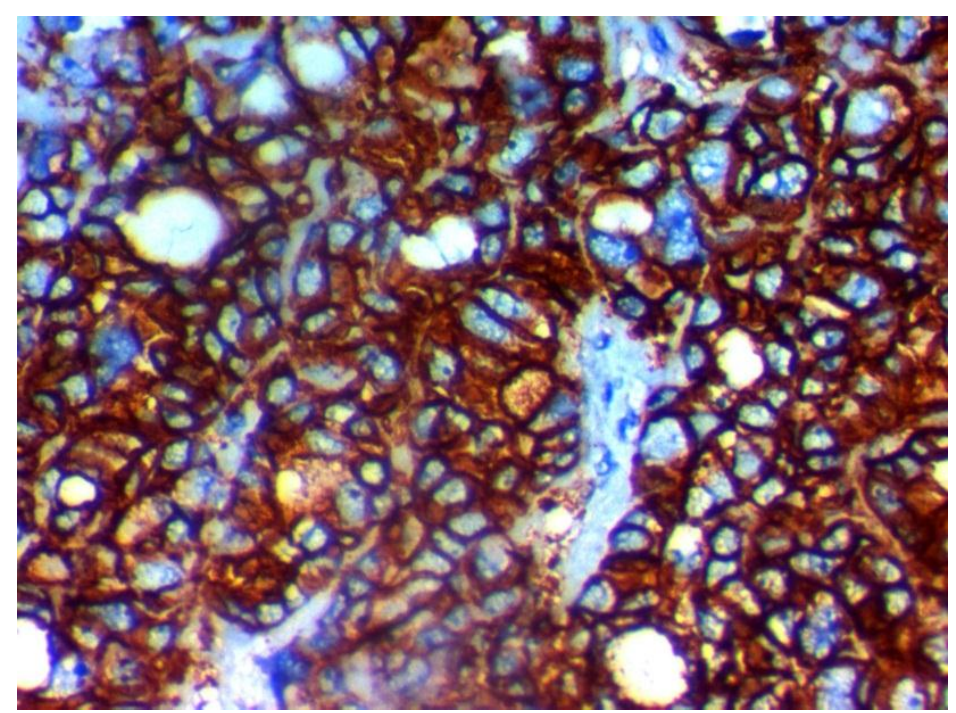

Fig 2 A

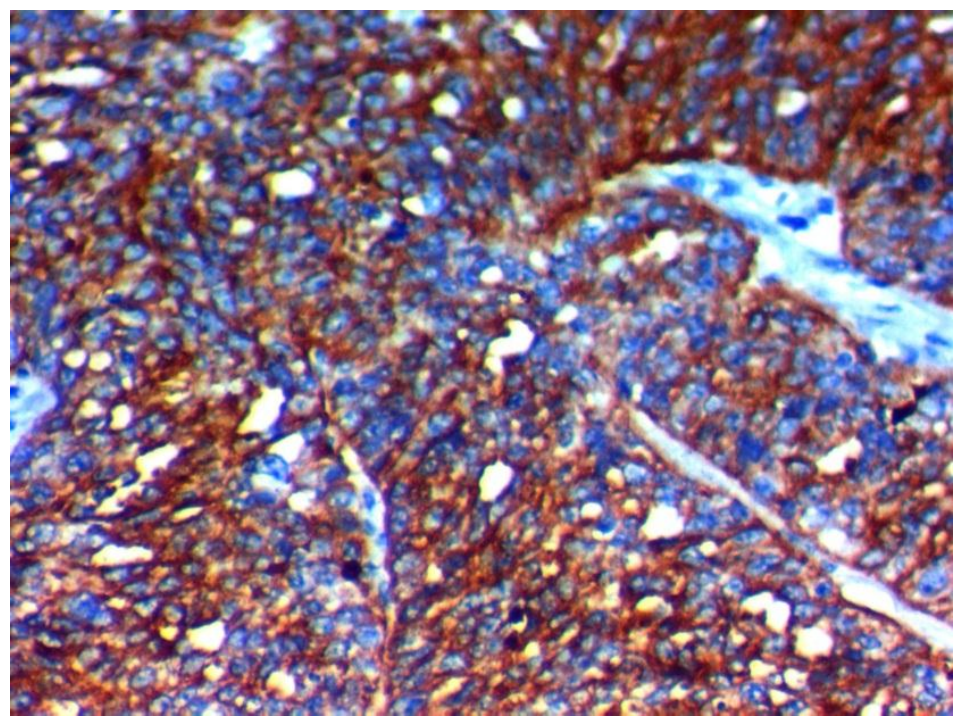

Fig 2 B 


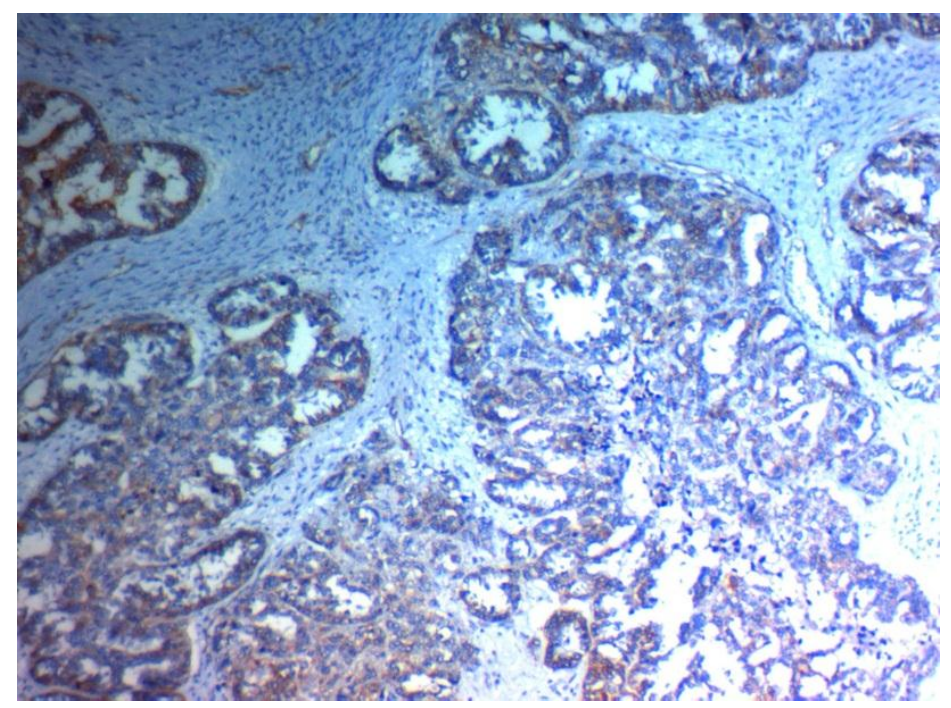

Fig $2 \mathrm{C}$

Figure2:-Immunohistochemical staining of Tau-protein in serous ovarian carcinoma (SOC): (A) High expression in the cytoplasm of low grade SOC stage IVx400. (B) High expression in the cytoplasm of low grade SOC stage III $\mathrm{x} 400$. ) (c) low expression in the cytoplasm of low grade SOC stage IIx100

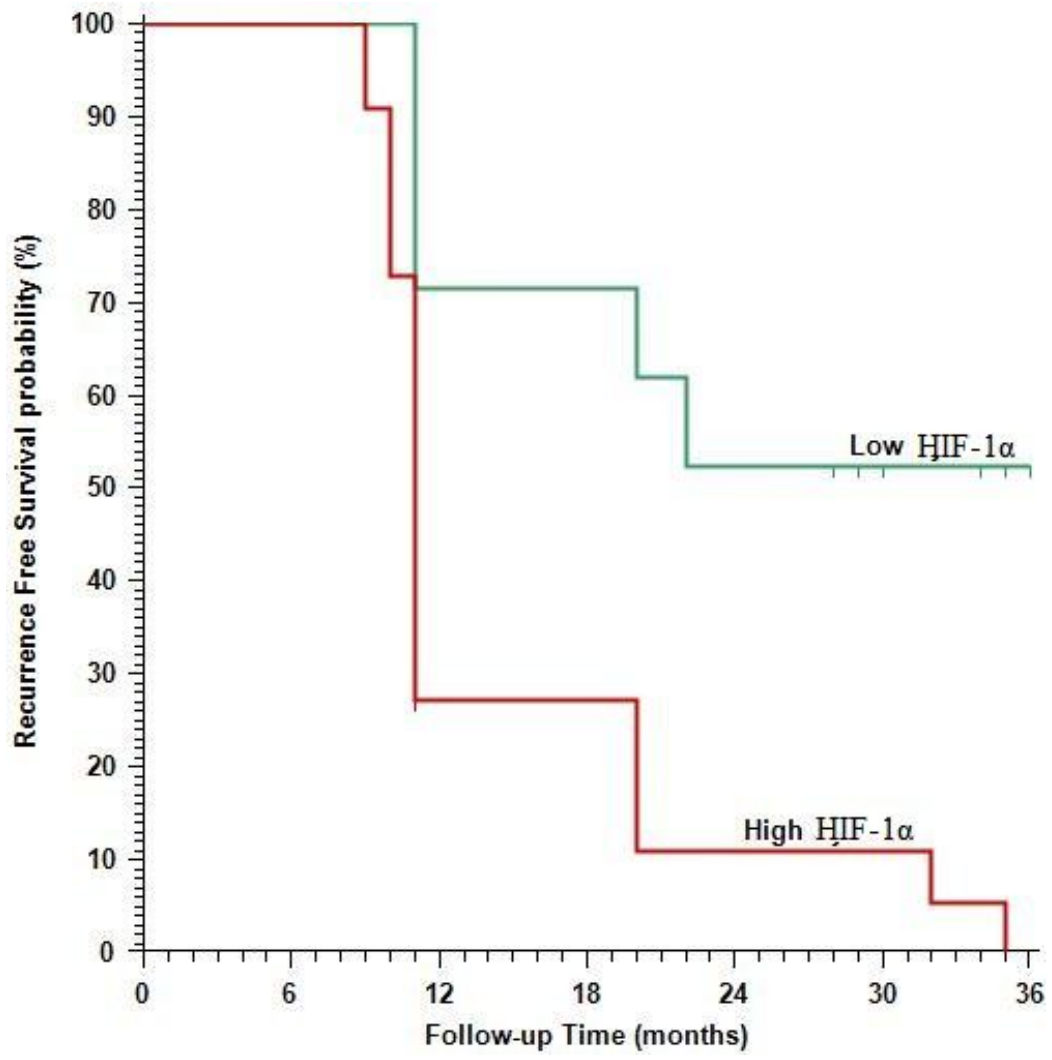

Fig 3 A 


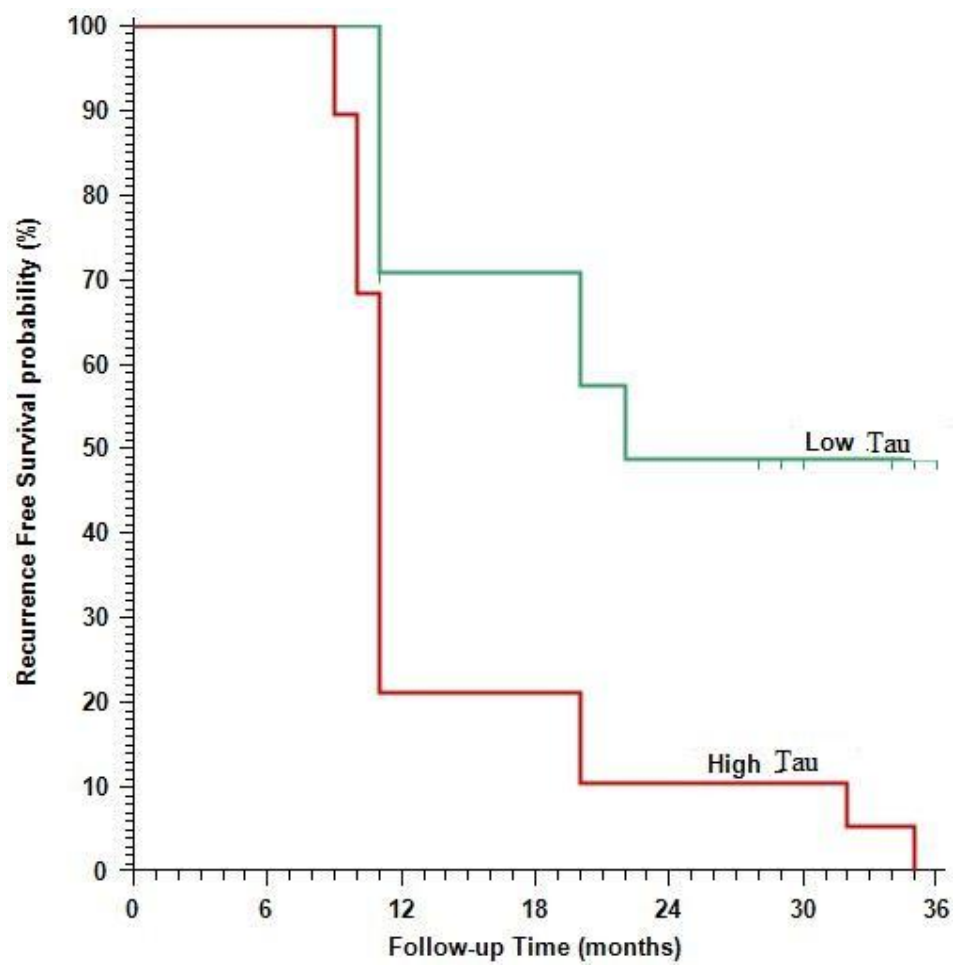

Fig 3 B

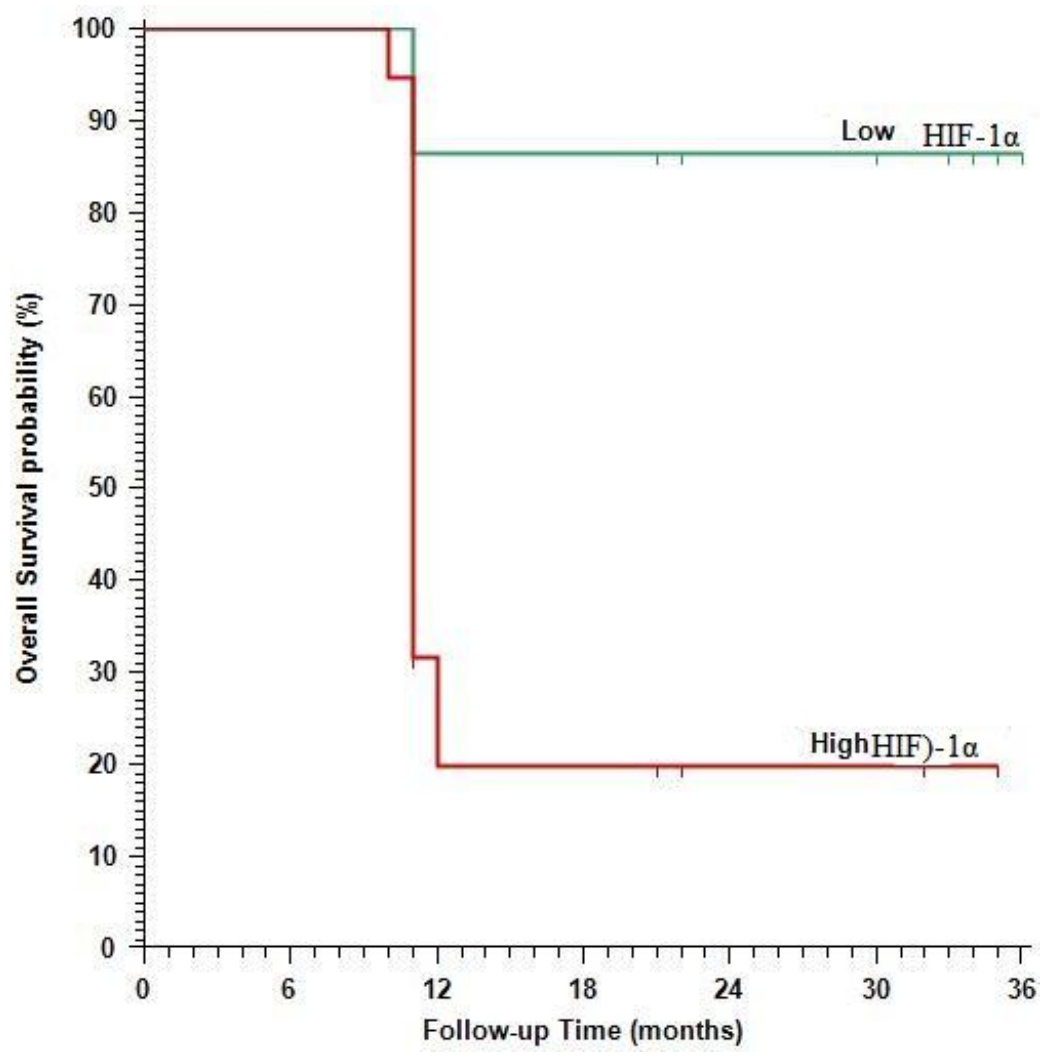

Fig $3 \mathrm{C}$ 


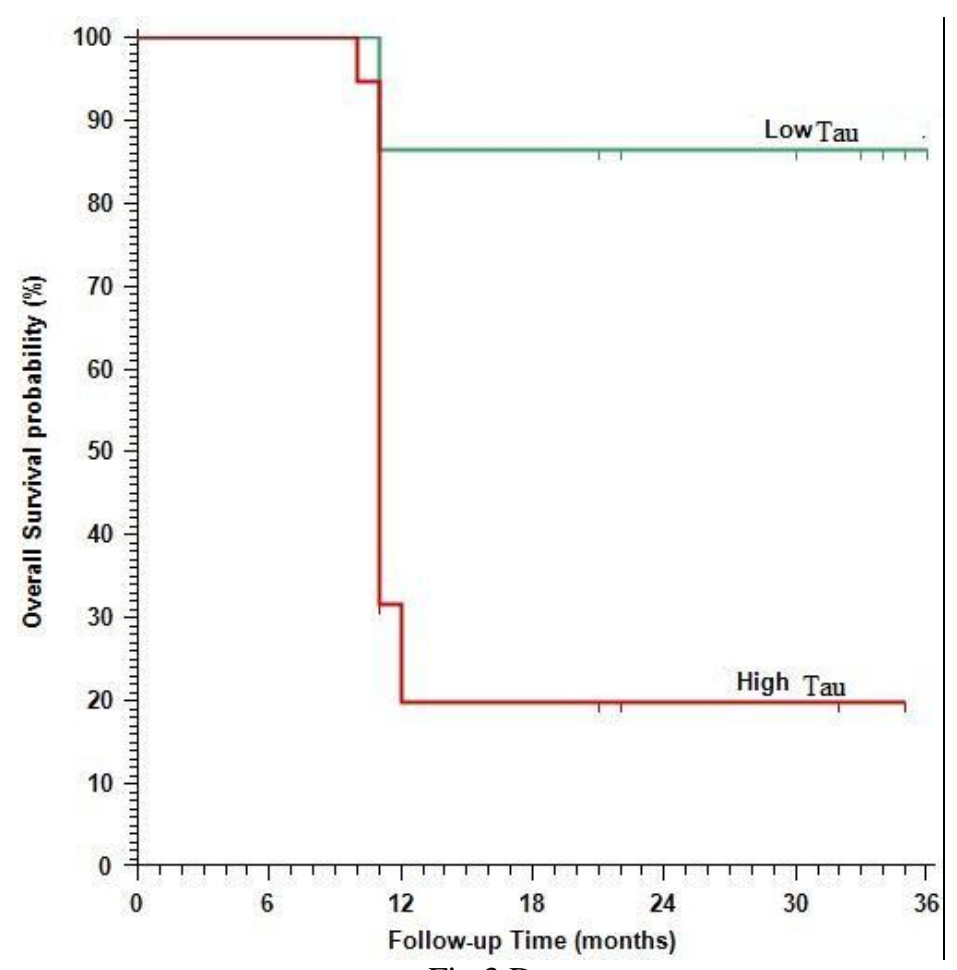

Fig 3 D

Figure 3:-Kaplan Meier Survival curves, of recurrence Free Survival \& overall Survival; (A \& C) Stratified by Hypoxia-Inducible Factor (HIF)-1 $\alpha$ (B \& C) Stratified by Tau-protein.

\section{Discussion:-}

Many previous studies tried to detect the roles of tissue hypoxia in malignant solid tumors in invasion, progression and resistance to chemotherapy in these tumors mainly SOC as it is a serious and fatal female malignancy [16]. We tried to assess severity of hypoxia in such tumor and its negative consequences on patients' outcome by evaluating the expression of the endogenous hypoxia related protein HIF-1 $\alpha$ in SOC tissues and correlate its expression with clinical, pathological and prognostic parameters of patients. We have found that high expression of HIF-1 $\alpha$ is associated with unfavorable pathological criteria e.g. high grade and advanced stage and adverse prognostic parameters e.g. resistance to chemotherapy, tumor recurrence after successive therapy and poor 3 year survival rates.

Similarly, Osman et al., [15] found that HIF-1 $\alpha$ higher expression was related to large tumor size, multiplicity, bilaterality and advanced stage of the tumor, and Aces et al., [17], who proved that HIF-1 $\alpha$ was overexpressed in advanced stages of SOC than early stages. Our results were explained by presence of larger areas of hypoxia in larger tumors.

Additionally, Jie et al., [16] \& Jin et al., [18] have detected the association of HIF-1 $\alpha$ higher expression levels with chemoresistance and dismal outcome in SOC patients and explained their results by that HIF-1 $\alpha$ leads to induction of epithelial mesenchymal transition in SOC cells which leads to acquiring mesenchymal criteria and dismal outcome. Moreover, Zheng et al., [19], stated that HIF-1 $\alpha$ is a negative prognostic parameter for hepatocellular carcinoma patients (HCC).

Shimogai R et al., [20], explained the association between higher HIF-1 $\alpha$ and poor our come of SOC patients that such type of tumor has many solid areas and papillae which increased areas of hypoxia and hypoxic mediators in the tumor that lead to unfavorable prognostic parameters. So evaluation of HIF-1 $\alpha$ expression could expect prognosis of patients with SOC. 
In the current study we have proved the association of increased HIF-1 $\alpha$ expression and resistance to chemotherapy which clarified the relation between increased hypoxic regions in solid tumors and more dismal outcome but in contrast to our results Nakai et al. [21], have proved more response to chemotherapy in patients that have increased HIF-1 $\alpha$ expression, moreover, Birner et al. 2001, have found no influence of HIF-1 $\alpha$ expression on chemotherapy response in SOC patients. These discrepancies might be due to different evaluation method of HIF-1 expression, different clone of the antibody used different number of patients and follow-up period which yields different results [22\& 21], additionally, Nakai et al. [21], have used the western blot method for evaluation of HIF-1 $\alpha$ expression and they have not considered the cytoplasmic non-functional HIF-1 $\alpha$ so they have overestimated the association between HIF-1 $\alpha$ and therapy response.

We have found an association between increased HIF-1 $\alpha$ expression and shorter 3 years survival rate similarly, Nakai et al., [21], have proved the similar association between increased HIF-1 $\alpha$ expression and shorter 5 year survival rate found a shorter 5-year OS has been described in patients with high HIF-expression, while Shimogai R et al., [20] have found no association between HIF-1 $\alpha$ expression and patients survival.

SOC is a fatal disease with high invasiveness and metastases power in addition to higher incidence of metastases which leads to dismal outcome. So, an essential step of its management is inhibition of its invasion, spread, resistance to chemotherapy and detection of novel therapeutic targets [23]. Liu et al., [24], have found the association between HIF- $1 \alpha$ increased expression and cancer progression by increasing invasion and metastases so targeted therapy against HIF- $1 \alpha$ could improve patients' prognosis and decreased chemoresistance especially in a fatal tumor like SOC.

Recent researchers have detected that HIF- $1 \alpha$ inhibitors are able to block malignant progression, and Zhang et al., [25], studied the role of digoxin as an HIF- $1 \alpha$ inhibitor which could suppress malignant growth by inhibiting synthesis of HIF-1 $\alpha$. Zagzag et al. [26], have clarified that geldanamycin inhibits glioma cells invasion and migration by antagonizing HIF-1 $\alpha$ actions.

We have proved the association between Tau-protein overexpression, poor pathological and prognostic parameters in SOC patients in addition to resistance to platinum based chemotherapy and unfavorable survival rates.

Our results are similar to results of Smoter et al. [15], who proved that low Tau-protein levels are associated with good response to chemotherapy. The association between Tau-protein expression and chemosensitivity is explained by understanding mechanisms of paclitaxel's action as it is considered competitive to usual action of Tau protein, which means that Paclitaxel could be able to bind beta-tubulin on to inner surface of the microtubules, in the same site of Tau protein binding [27], so increased the levels of Tau protein on surfaces of the microtubules might lead to difficult paclitaxel attachment to them, interfere with its work on SOC cells.

Moreover low levels of Tau-protein expression will result in better connection of paclitaxel to the microtubules, more effective chemotherapy action, higher chemosensitivity and better survival rates[14].

The same results were detected in cancer breast in which low levels of Tau-protein is associated with mor complete response to paclitaxel bases chemotherapy, so Tau- protein inhibition will lead to enhancement of paclitaxel activity in such type of cancer [9]. Tanaka et al. [28], have proved the same results that breast cancer patients with Tauprotein negativity are more sensitive to paclitaxel than patients with Tau-protein negativity. Which proved our results regarding the predictive role of Tau-protein in SOC, additionally, Wu et al.[29] confirmed the predictive and prognostic role of low Tau-protein expression regarding sensitivity to paclitaxel based therapy in gastric cancer.

In cancer cells with low levels of Tau-expression paclitaxel has many roles as it increased the rate of apoptosis in those cells. Paclitaxel combines with tubulin easily in cases of low Tau protein expression levels while higher levels of Tau-protein leads to stabilization of the microtubules protecting SOC cells from the harmful paclitaxel effects, that leads to drug resistance. But as the mechanism of paclitaxel action on cancer cells is complicated so resistance mechanisms to paclitaxel needs further studies [30].

Similarly, Abd elaziz et al., [31] proved the same association of Tau-protein and unfavorable outcome of SOC patients. In contrast to our results, Steffensen $\boldsymbol{e t}$ al., [32], have reported that levels of Tau-protein expression were not associated with survival rates. Different results also were found by Shao et al., [33], that increased Tau-protein is a good prognostic marker in breast cancer patients but they did not explained their results but this variable role 
might be due to different work of Tau-protein action in different cancer type. These conflicting results about the prognostic roles of Tau-protein expression in SOC needs further studies to prove our results.

As we have studied both HIF-1 $\alpha$ and Tau-protein expression in SOC and we have found significant positive association between expression of them and their combined expression was related to unfavorable criteria, these results point to the association between Tau-protein related chemotherapy resistance and higher levels of hypoxia in solid tumors like SOC. Our study was the first to explain the relation between both HIF-1 $\alpha$ and Tau-protein expression in SOC and patients' prognosis, so further studies are needed to prove our results.

\section{Summary\& Conclusion:-}

HIF-1 $\alpha$ that is a marker of tumor hypoxia is overexpressed in SOC tissues and is related to unfavorable outcome of patients. Tau-protein is related to resistance to chemotherapy in SOC patients that leads to short survival rates. We have found positive association between both markers so targeted therapy against them could improve SOC patients' prognosis.

\section{Recommendations:-}

Further prospective studies on larger number of patients are needed to prove our results.

\section{References:-}

1. Konstantinopoulos PA and Matulonis UA. Current status and evolution of preclinical drug development models of epithelial ovarian cancer. Front Oncol 2013; 3: 296.

2. Jayson GC, Kohn EC, Kitchener HC and Ledermann JA. Ovarian cancer. Lancet 2014; 384: 1376-1388.

3. Ying H, Qu D, Liu C, Ying T, Lv G, Jin SH and XU H. Chemoresistance is associated with Beclin-1 and PTEN expression in epithelial ovarian cancers ONCOLOGY LETTERS 2015;9: 1759-1763,

4. Rajanbabu A, Kuriakose S, Ahmad SZ et al. Evolution of surgery in advanced epithelial ovarian cancer in a dedicated gynaecologic oncology unit-seven year audit from a tertiary care centre in a developing country. Ecancer medical science 2014; 8: 422.

5. Takebe N, Miele L, Harris PJ et al.Targeting Notch, Hedgehog, and Wnt pathways in cancer stem cells: clinical update. Nat Rev Clin Oncol 2015; 12: 445-64.

6. Ramos P and Bentires-Alj M. Mechanism-based cancer therapy: resistance to therapy, therapy for resistance. Oncogene 2015; 34: 3617-26.

7. Mabjeesh NJ, Amir S. Hypoxia-inducible factor (HIF) in human tumorigenesis. Histol Histopathol.2007; 22:559-72.

8. Wilson KG, Tennant AD, McKeating AJ. Hypoxia inducible factors in liver disease and hepatocellular carcinoma: current understanding and future directions. J Hepatol. 2014;61:1397-406.

9. Rouzier $\mathbf{R}^{1}$, Rajan $\mathbf{R}$, Wagner $\mathbf{P}$ et al.Microtubule-associated protein tau: amarker of paclitaxel sensitivity in breast cancer. Proc Natl Acad Sci USA 2005, 102:8315-20

10. Cook, C.; Stankowski, J.N.; Carlomagno, Y et al: A new key to unlock tau's role in neurodegeneration. Alzheimers Res. Ther. 2014, 6, 29.

11. Kurman RJ, Carcangiu ML, Herrington CS et al. WHO Classification of Tumors of Female Reproductive Organs. 4th ed.Lyon: International Agency for Research on Cancer. 2014

12. Prat J . FIGO Committee on Gynecologic Oncology. Staging classification for cancer of the ovary, fallopian tube, and peritoneum. Int J Gynaecol Obstet 2014; 124 (1):1-5.

13. Hsu SM, Raine $\mathbf{L}$ and Fanger $\mathbf{H}$. Use of avidin-biotin-peroxidase complex (ABC) in immunoperoxidase techniques: a comparison between $\mathrm{ABC}$ and unlabeled antibody (PAP) procedures. J HistochemCytochem. 1981; 29:577-580.

14. Smoter M, Bodnar L, Grala B, et al. Tau protein as a potential predictive marker in epithelial ovarian cancer patients treated with paclitaxel/platinum first-line chemotherapy. J Exp Clin Cancer Res. 2013 Apr 30; 32:25. doi: 10.1186/1756-9966-32-25.

15. Osman NA, Abd El-Rehim DM and Kamal IM. Defective Beclin-1 and elevated hypoxia-inducible factor (HIF)-1 $\alpha$ expression are closely linked to tumorigenesis, differentiation, and progression of hepatocellular carcinoma. Tumour Biol; 2015; 36(6): 4293-4299.

16. Jie Qin1, Yan Liu2, Yongkui Lu2 et al. Hypoxia-inducible factor 1 alpha promotes cancer stem cells-like properties in human ovarian cancer cells by up regulating SIRT1expression SCieNTifiC REPOrts. 2017 
17. Acs G, Xu X, Chu $\mathbf{C}$ et al. Prognostic significance of erythropoietin expression in human endometrial carcinoma. Cancer 2004;100:2376-86.

18. Jin, Y., Wang, H., Liang, $\mathbf{X}$ et al. Pathological and prognostic significance of hypoxia-inducible factor 1alpha expression in epithelial ovarian cancer: a meta-analysis. Tumour biology: the journal of the International Society for Oncodevelopmental Biology and Medicine 2014;35, 8149-8159, doi:10.1007/s13277-014-2059-x,

19. Zheng SS, Chen XH, Yin $\mathbf{X}$ et al. Prognostic significance of HIF-1alpha expression in hepatocellular carcinoma: a meta-analysis. PLoS One. (e65753):2013;1-7.

20. Shimogai R, Kigawa J, Itamochi H, et al. Expression of hypoxiainducible factor 1alpha gene affects the outcome in patients with ovarian cancer. Int J Gynecol Cancer 2008;18:499-505.

21. Nakai H,WatanabeY, Ueda H, Hoshiai H.. Hypoxia inducible factor 1- alpha expression as a factor predictive of efficacy of taxane/platinum chemotherapy in advanced primary epithelial ovarian cancer. Cancer Lett $2007 ; 251: 164-7$.

22. Birner P, Schindl M, Obermair A et al.. Overexpression of hypoxia-inducible factor 1alpha is a marker for an unfavorable prognosis in early-stage invasive cervical cancer. Cancer Res 2000; 60:4693-6.

23. Ruscito I, Gasparri ML, Marchetti C, et al.. Cediranib in ovarian cancer: state of the art and future perspectives. Tumour Biol 2016; 37: 2833-2839.

24. Ting Liu, Le Zhao, Huilian Hou et al. Ginsenoside 20(S)-Rg3 suppresses ovarian cancer migration via hypoxia-inducible factor 1 alpha and nuclear factor-kappa B signals Tumor Biology: 2017;1- 10

25. Zhang H, Qian DZ, Tan YS, et al.. Digoxin and other cardiac glycosides inhibit HIF-1alpha synthesis and block tumor growth. Proc Natl Acad Sci U S A 2008;105(50): 19579-19586.

26. Zagzag D, Nomura M, Friedlander DR, et al.. Geldanamycin inhibits migration of glioma cells in vitro: a potential role for hypoxia-inducible factor (HIF-1alpha) in glioma cell invasion. J Cell Physiol 2003;196(2): 394-402.

27. Kar S, Fan J, Smith MJ et al: Repeat motifs of tau bind to the insides of microtubules in the absence of taxol. EMBO J 2003, 22:70-77.

28. Tanaka S1, Nohara T, Iwamoto M, et al.: Tau expression and efficacy of paclitaxel treatment in metastatic breast cancer. Cancer Chemother Pharmacol 2009, 64:341-6.

29. Wu H, Huang M, Lu M et al.Regulation of microtubule-associated protein tau (MAPT) by miR-34c-5p determines the chemosensitivity ofgastric cancer to paclitaxel. Cancer Chemother Pharmacol. 2013 May; 71(5):1159-71. doi: 10.1007/s00280-013-2108-y.

30. Wang Q \& Wang $\mathbf{N} \&$ Shao $\mathbf{G}$ et al. Relationship Between Gastric Cancer Tau Protein Expression and Paclitaxel Sensitivity Pathol. Oncol. Res. (2013) 19:429-435

31. Abd elaziz L, Younis $\mathbf{S}$ and Abd el hak M Microtubule associated protein tau as a marker of response to taxene based chemotherapy in primary epithelial ovarian cancer Life Science Journal 2014;11(12)

32. Steffensen KD, Smoter M, Waldstrøm M, et al.,: Resistance to first line platinum paclitaxel chemotherapy in serous epithelial ovarian cancer: the prediction value of ERCC1 and Tau expression. Int J Oncol. 2014 May; 44(5):1736- 44.

33. Shao YY, Kuo KT, Hu FC, et al. Predictive and prognostic values of tau and ERCC1 in advanced breast cancer patients treated with paclitaxel and cisplatin. Jpn J Clin Oncol. 2010; 40:286-293. doi: 10.1093/jjco/hyp184. 